\title{
Imperatives and politeness in Dutch
}

\author{
Helen de Hoop, Jetske Klatter, Gijs Mulder and Tijn Schmitz \\ Radboud University Nijmegen
}

\begin{abstract}
Imperatives are usually thought of as direct and therefore impolite. However, imperatives such as Have some coffee, Enjoy your holiday, or Sleep well are not considered impolite. The reason seems to be that these imperatives refer to actions that are beneficial to the hearer only. We make a distinction between two types of imperatives, those referring to actions that are beneficial to the speaker and those that are beneficial to the hearer. We have conducted an experiment in order to examine the relation between the two types of imperatives and how they are perceived by speakers of Dutch. The results show that there is indeed a significant difference in interpretation between the two types of imperatives in Dutch. In addition, we have tested the effects of adding a politeness marker alsjeblieft 'please' or discourse particles to the imperatives.
\end{abstract}

Keywords: imperative, politeness, requests, experiment, discourse particles

\section{Introduction}

In classical pragmatics, imperative sentences are usually thought of as direct and therefore impolite. For instance, Searle (1975: 64) in his study of indirect speech acts notes that "ordinary conversational requirements of politeness normally make it awkward to issue flat imperative sentences (e.g., Leave the room) (...), and we therefore seek to find indirect means to our illocutionary ends (e.g., I wonder if you would mind leaving the room)." Brown \& Levinson (1978: 74) assume that doing a face threatening act "baldly, without redress, involves doing it in the most direct, clear, unambiguous and concise way possible (for example, for a request, saying 'Do X!')." They argue that this would be in accordance with Grice's (1975) maxims, and that politeness is a major source of deviation from these maxims. Grice (1975: 47) also acknowledges that apart from the maxims that are in accordance with his Cooperative Principle, there are "all sorts of other maxims (aesthetic, social, or moral in character), such as 'Be polite', that are also normally observed by participants in talk exchanges", which led various scholars to assume maxims of politeness 
(e.g., Leech 1983). Recently, Pfister (2010) proposed a Gricean theory of politeness that incorporates insights from Brown \& Levinson's (1978) politeness theory.

Brown \& Levinson (1978: 100) consider direct imperatives to "stand out as clear examples of bald-on-record usage". They characterize situations in which these imperatives may be used as situations in which the speaker does not fear retribution from the hearer, for example when the danger to the hearer's face is very small "as in offers, requests, suggestions that are clearly in $\mathrm{H}$ [earer]'s interest and do not require great sacrifices of S[peaker] (e.g., 'Come in' or 'Do sit down')" (Brown \& Levinson 1978: 74).

Thus, imperatives can be used for various illocutions, as was also recognized in studies on Dutch imperatives (Proeme 1984; De Haan 1992), and therefore cannot be considered impolite per se. In fact, more recent studies on politeness (cf. Watts 2003) emphasize that no linguistic structure is inherently polite or impolite. The focus in the literature, however, has been on requests, and imperatives are considered the most direct and least polite ways to express these (e.g., Blum-Kulka 1987; Trosborg 1995). Blum-Kulka (1987) finds that the most indirect request strategies are not necessarily judged as the most polite. That is, whereas hints (e.g., You've left the kitchen in a right mess, as a request to clean up the kitchen) are considered the most indirect, query preparatories (e.g., Could you clean up the mess in the kitchen?) are considered the most polite, both in English and Hebrew. However, at the other end of the scales, imperatives (Clean up the kitchen) are found to be considered the most direct as well as the least polite way of expressing a request, both in English and in Hebrew.

The purpose of the present paper is to investigate the relation between imperatives and politeness. What is new in our approach is that we do not investigate alternative forms of making speech acts, notably requests (cf. Clark \& Schunk 1980; Blum-Kulka 1987; Curl \& Drew 2008; Rossi 2012), but that we investigate one specific linguistic form, that is, imperative sentences (cf. Hamblin 1987; Jary \& Kissine 2014), and that our point of departure is the distinction that can be made between imperatives that refer to actions that are in the speaker's interest (e.g, requests) and imperatives that refer to actions that are in the hearer's interest (e.g., offers such as Have some coffee, or invitations such as Come in). For the sake of coherence, we restrict our study to the verb-stem imperative, excluding the alternative infinitivus pro imperativo.

In Section 2 we present three hypotheses on the relation between these two types of imperatives and their interpretation in Dutch. Section 3 reports on an experiment that we carried out in order to test our hypotheses, and Section 4 presents the conclusion. 


\section{Three hypotheses on the interpretation of imperatives in Dutch}

The general meaning of imperatives in Dutch is defined as follows by Fortuin \& Boogaart (2009: 652): "By using the imperative, the speaker gives an impulse to the addressee to realize the imperative situation." They use this general definition to cover both directive imperatives and conditional imperatives, but it is also in accordance with the two types of imperatives that we distinguish, those in the speaker's interest and those in the hearer's interest.

\subsection{Speaker's versus hearer's interest}

Hamblin (1987) distinguishes between willful imperatives proper, such as commands, requests, and demands, and non-willful ones, such as suggestions, and instructions and recipes. He points out that the difference between the two can already be found in Hobbes (1651) who distinguishes between commands and advice as follows (see also Mulder 1998: 102):

Command is where a man saith, "Do this," or "Do not this," without expecting other reason than the will of him that says it. (...)

Counsel is where a man saith, "Do," or "Do not this," and deduceth his reasons from the benefit that arriveth by it to him to whom he saith it. (...)

Therefore between counsel and command, one great difference is that command is directed to a man's own benefit, and counsel to the benefit of another man.

(Hobbes 1651, Chapter XXV - Of Counsel)

Thus, two types of imperatives can be observed that refer to actions that are beneficial to either the speaker or to the hearer. Commands or requests that take the form of imperatives are usually considered impolite, but this will not hold for imperatives that are used for offers, invitations, or advice, which are all in the hearer's interest. The two types are illustrated in (1) and (2) in Dutch.

(1) Ruim de keuken op clean the kitchen up 'Clean up the kitchen.'

(2) Neem een stukje taart take a piece cake 'Have a piece of cake.'

Our first hypothesis can be formulated as follows:

Hypothesis 1

Imperatives that are beneficial to the hearer will receive a more positive interpretation than imperatives that are beneficial to the speaker. 
In the experiment, we deliberately avoid the terms 'polite' and 'impolite', and prefer 'positive' and 'negative' instead, since we are interested in people's interpretations of imperative sentences. In ordinary usage 'polite' and related terms are vague and variable (cf. Leech 2014:47). A speaker of a 'polite' utterance is not necessarily considered as having a 'nice' or 'friendly' attitude, for example.

\subsection{Adding the politeness marker alsjeblieft 'please' to imperatives}

Sato (2008: 1254) discerns two main characterizations of please in the literature, either as a politeness marker or as a request marker. The two seem closely related. That is, the function of please as a politeness marker is "to soften the inherently face-threatening content carried by the specific request and/or by the formal aspects of imperative sentences", whereas please as a request marker "is grounded in both its attested usage in requests and its diminishing role as a non-marked politeness marker (Sato 2008: 1254)." Wichmann (2004), who considers please a request marker, notes that the presence of please will lead the hearer to infer that the utterance is intended as a request, rather than, for example, a question. That is, adding please to an imperative in English may change a command into a request, when the action expressed by the imperative is in the speaker's interest. However, it may also turn an imperative that expresses an action in the hearer's interest, such as an advice, into a request, which is then in the speaker's interest. In that case, the addition of please would not make the utterance more polite. In fact, adding please may sometimes make an utterance less polite, e.g., cold, distant, sarcastic, or more insistent (cf. Ervin-Tripp 1976; Curl \& Drew 2008).

Although we have not found any literature on the effect of adding Dutch alsjeblieft 'please' to imperatives, our intuitions as native speakers are that imperatives which are beneficial to the speaker do not necessarily become more polite when alsjeblieft 'please' is added, while imperatives beneficial to the hearer may even become less polite, because they now get interpreted as a kind of request. That is, adding the marker alsjeblieft 'please' to an imperative makes the action that is normally mainly in the hearer's interest to an action that is also or even more in the speaker's interest (see (4)).

(3) Ruim alsjeblieft de keuken op clean please the kitchen up 'Clean up the kitchen, please.'

(4) Neem alsjeblieft een stukje taart take please a piece cake 'Have a piece of cake, please.' 
Both (3) and (4) can be interpreted as said by a speaker who is getting irritated or annoyed. Thus, in Dutch adding alsjeblieft 'please' does not seem to make imperatives more polite. Our second hypothesis is formulated as follows:

Hypothesis 2

Adding alsjeblieft 'please' makes an imperative more negative, especially in the case of imperatives that are beneficial to the hearer.

\subsection{Adding discourse particles to imperatives in Dutch}

Notoriously, discourse particles have a wide variety of functions, such as structuring the discourse, marking the relation between speaker and hearer, conveying emotion, or affecting speech acts (cf. for example Hogeweg et al. 2012). Adding discourse particles to directive speech acts is usually considered a strategy of (negative) politeness called 'hedging' (Brown \& Levinson 1978: 151). Dutch is a language that has many discourse particles, but Vismans (1994) points out that not all discourse particles in Dutch make an utterance more polite, some actually appear to make the utterance less polite. This appears to be related to their function, either 'reinforcing' or 'mitigating. Of the six discourse particles investigated by Vismans (1994) that can occur with imperatives in Dutch, four can be understood as reinforcing the speech act (dan, eens, ook, toch) whereas two others are used to mitigate the speech act, maar and even. Since only the mitigating particles maar and even are assumed to make an imperative more polite, we chose the combination of these two particles (maar even) for our investigation of the effect of adding particles on the perceived politeness of the two types of imperatives. Of course, there are also sentence-final particles that have been argued to have different effects when they are added to imperatives (cf. Kirsner 2003), but we have limited ourselves to the effect of adding maar and even as sentence-medial particles. The two types of imperatives to which we have added the two mitigating discourse particles are illustrated in (5) and (6). Because the particles maar and even cannot be properly translated in English, we have translated them by adding a tag question, which is considered a similar politeness strategy in the domain of imperatives (Brown \& Levinson 1978: 152; Vismans 1994).

(5) Ruim maar even de keuken op clean PRT PRT the kitchen up 'Clean up the kitchen, will you?'

(6) Neem maar even een stukje taart take PRT PRT a piece cake 'Have a piece of cake, will you?' 
We agree with suggestions made in the literature that addition of the discourse particles maar and even to imperatives has a mitigating function. However, we expect this effect to be stronger in the case of imperatives that are beneficial to the speaker. As we have argued above, imperatives that are beneficial to the hearer, are not impolite and therefore they do not need to be mitigated in order to be less face threatening. Our third hypothesis can be formulated as follows:

Hypothesis 3

Adding discourse particles will make an imperative more positive, especially in the case of imperatives that are beneficial to the speaker.

In the next section we will report on the experiment that we conducted in order to test our three hypotheses.

\section{The experiment}

\subsection{Methodology}

\subsubsection{Participants}

The participants in the experiment were 37 ( 29 female, 8 male) native speakers of Dutch, with an average age of 24.6 (standard deviation: 7.9, minimum: 18, maximum: 59). They received either an award of 10 euros or 1 study credit point from Radboud University Nijmegen for their participation. The participants were all native speakers of Dutch. The data of one participant were excluded from the analysis because of particular language errors (e.g., article use), indicating that this person was not a native speaker.

\subsubsection{Materials}

Two types of imperative sentences were used in the experiment: imperatives beneficial to the speaker (e.g., Ruim de keuken op 'Clean up the kitchen'), and imperatives beneficial to the hearer (e.g., Maak er een leuke dag van 'Have a nice day'). All sentences were created in three conditions: 'Bare', 'Alsjeblieft' (e.g., Maak er alsjeblieft een leuke dag van 'Have a nice day, please'), and 'Particles' (e.g., Maak er maar even een leuke dag van 'Have a nice day, will you?). The position of alsjeblieft 'please' and the particles was constantly kept in the second position in the sentence, to avoid possible side effects of different sentence positions (initial, medial, final). Furthermore, particles other than those in the experimental manipulation were avoided in the test material, in order to ensure that the effects found could only be related to the experimental manipulation. 
30 sets of imperative sentences were constructed, 15 of each type of imperative. In addition to these sentences, 30 fillers were created. These sentences were non-imperatives (e.g., declaratives, questions, exclamations). The filler sentences were equally divided in positive, negative, and neutral sentences, of which examples are given in (7)-(9), respectively.

(7) Wat een mooi cadeau! what a nice present 'What a nice present!'

(8) Ik verveel me dood hier

I bore me dead here 'I’m so bored.'

(9) Ik ga vandaag op de fiets

I go today on the bike

'I'll take the bike today'.

\subsubsection{Pretest}

To get some ideas about how people would interpret the imperative sentences we constructed, we conducted a pretest, in which 26 people read a subset of the sentences and mentioned properties they considered suitable to characterize the speaker who uttered the imperative. Furthermore, they had to come up with a short context in which the sentence could be used. In this way, we were able to see if the sentences were interpreted in a consistent way. From the properties that participants used in the pretest to characterize the speaker of the utterance, the most frequent ones were selected to be used in the main experiment. This led to the following selection of properties, in alphabetical order: aardig 'nice' (positive), attent 'considerate' (positive), bazig 'bossy' (negative), boos 'angry' (negative), chagrijnig 'bad-tempered' (negative), diplomatiek 'diplomatic' (positive), geïrriteerd 'irritated' (negative), geruststellend 'reassuring' (positive), kortaf 'curt' (negative), neutraal 'neutral' (neutral), ongeduldig 'impatient' (negative), onvriendelijk 'unfriendly' (negative), vriendelijk 'friendly' (positive), zorgzaam 'caring' (positive).

The results of the pretest were in accordance with all three hypotheses. Besides, the contexts participants came up with were fairly consistent. For the imperatives beneficial to the speaker, the bare ones were mainly interpreted as indicating social distance, such that the speaker has power over the hearer and gives them a direct order. Adding particles often turned the command into a request. When alsjeblieft was added, the speaker was often characterized as being irritated. For imperatives beneficial to the hearer, the bare ones were mainly interpreted as an invitation or offer, whereas adding particles often turned them into an advice or suggestion. 
Interestingly, when alsjeblieft was added, the imperatives seemed to be interpreted more as if the intended action were in the speaker's instead of the hearer's interest. For example, a context that was provided for Neem alsjeblieft een stukje taart 'Have a piece of cake, please' was a birthday party where nobody wanted to have a piece of that horrible carrot cake.

\subsubsection{Design}

The first independent variable in the main experiment, Interest, was a within-subjects factor with two levels: Speaker's interest and Hearer's interest. Each sentence was either hearer's interest or speaker's interest, so Interest was a between-items factor. The second independent variable, Sentence type, was a within-subjects factor with three levels: Bare, Alsjeblieft, and Particles. For each item, a variant of all three conditions was made, so Sentence type was a within-items factor as well.

Each participant saw each stimulus in exactly one condition, leading to a total of 30 experimental stimuli (15 speaker's interest, 15 hearer's interest; 10 items per Sentence type). These were interspersed with a total of 30 fillers. Pseudorandomization ensured that the sentence types and fillers were equally divided over the list, where never more than two items of the same category followed each other. The second and third list were based on the first list by using a Latin square: Where a Bare imperative was used in the first list, the Alsjeblieft imperative of the same set was used in the second list, and the Particles imperative of the same set in the third list.

\subsubsection{Procedure}

The experiment, carried out in the CLS-lab at the Radboud University Nijmegen, was built with Qualtrics, an online platform for developing surveys. Participants were asked first to interpret an example sentence, Wanneer gaan we nou? ('When can we finally leave?'), and imagine the person who uttered it. The 14 properties were presented horizontally next to each other in alphabetical order and participants were instructed to choose one property that they thought would best characterize the speaker of the utterance. In the example, 'impatient' was chosen as a suitable property, but participants were told that there were no right or wrong answers. After choosing a property, they had to construct a small context of one of two sentences, which described a situation in which the sentence could be used. In the example, the following context was given: A family goes on vacation and one of the children has been waiting in the car for more than an hour before they finally leave. We assumed that by producing a context, participants would have to interpret the sentence more carefully, compared to when they would only have to choose a property. 
Participants got 60 minutes to complete the experiment, so with the total of 60 items (30 experimental, 30 fillers) they had approximately one minute per item. However, most participants did not use the full 60 minutes. Only one item at a time was presented and there was no option to see or adjust previous answers.

\subsubsection{Data analysis}

The dependent variable in the experiment was the property chosen. This was scored as Negative, Positive, or Neutral. Percentages were calculated for the amount of negative, positive, and neutral answers. In the statistical analysis, the amount of negative interpretations was compared with the amount of non-negative interpretations (thus, positive and neutral). The contexts were not analyzed as they were only used to force participants to interpret the sentences carefully.

\subsection{Results}

A Oneway ANOVA was conducted with the number of negative interpretations as dependent variable, and Interest, Sentence type, and their interaction as independent variables. A Bonferroni post-hoc test was used to investigate interactional group differences.

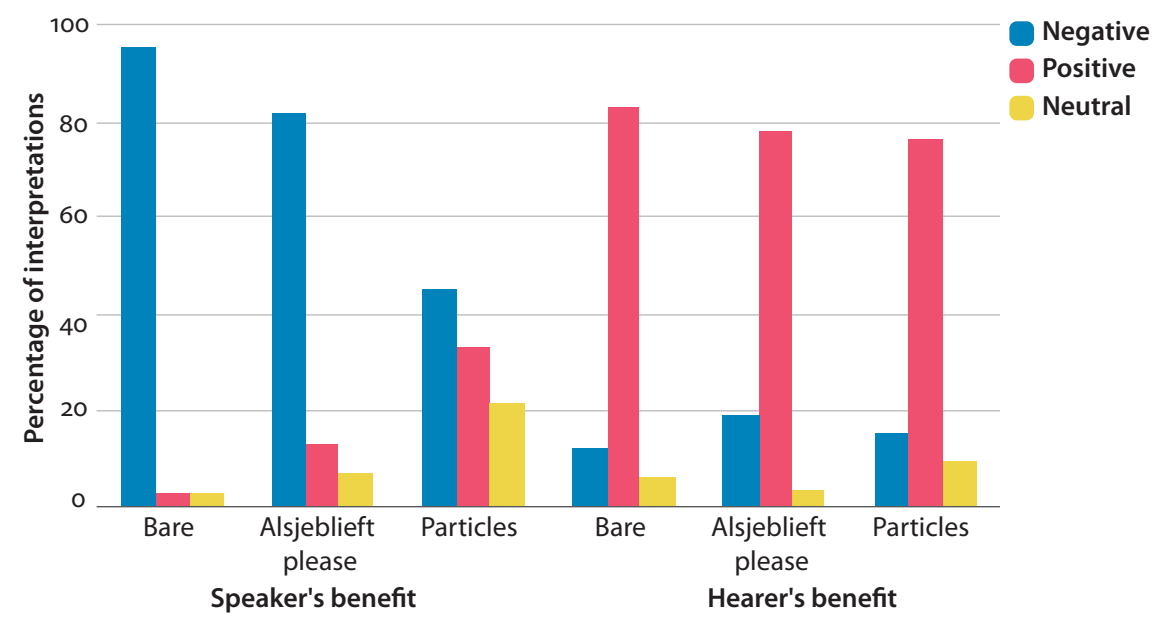

Figure 1. Overview of the results per group

An overview of the results is given in Figure 1. There was a main effect of Interest, indicating that imperatives beneficial to the speaker $(M=74.1, S D=27.7)$ were generally interpreted more negatively than imperatives beneficial to the hearer $(M=15.4, S D=19.2), F(1,84)=223.949, p<.001$. 
We also found a main effect of Sentence type, $F(2,84)=14.368, p<.001$. Predefined contrasts revealed that negativity of imperatives with alsjeblieft $(M=50.3, S D=37.0)$ did not significantly differ from negativity of bare imperatives $(M=53.9, S D=44.5), p=.454$. However, there was a significant difference between bare imperatives and imperatives with particles. Imperatives with particles $(M=30.0, S D=26.4)$ were interpreted significantly less negatively than bare imperatives $(M=53.9, S D=44.5), p<.001$.

The interaction between Interest and Sentence type was significant as well, $F(2,84)=, p<.001$. A Bonferroni post-hoc test showed that the effect of Interest was significant in all three sentence types (all $p$ 's $<.001$ ). The difference between speaker's interest $(M=95.6, S D=6.9)$ and hearer's interest $(M=12.2, S D=18.3)$ was largest in the Bare condition.

The hypothesis was that adding alsjeblieft would lead to a more negative interpretation, especially when the intended action was beneficial to the hearer. For imperatives beneficial to the speaker, sentences with alsjeblieft $(M=81.6, S D=17.0)$ seemed to be interpreted slightly less negative than bare sentences $(M=95.6$, $S D=6.9$ ), but this difference was not significant, $p=.661$. Using alsjeblieft in imperatives beneficial to the hearer $(M=18.9, S D=21.0)$ led to more negative interpretations than using bare imperatives $(M=12.2, S D=18.3)$, but this effect was not significant either, $p>.999$.

According to our prediction, adding particles would mainly lead to less negative interpretations in imperatives beneficial to the speaker. This indeed seems to be the case. For imperatives beneficial to the hearer, the difference between bare imperatives $(M=12.2, S D=18.3)$ and imperatives with particles $(M=15.0$, $S D=19.0$ ) was not significant, $p>.999$. However, for imperatives beneficial to the speaker, the difference between bare ones $(M=95.6, S D=6.9)$ and imperatives with particles $(M=45.0, S D=24.6)$ was significant, $p<.001$.

\subsection{Discussion}

Our first hypothesis was that imperatives in the hearer's interest receive a more positive interpretation than the ones that are in the speaker's interest. This hypothesis was confirmed by the data. The distinction between the two types of imperatives appears to be of vital importance to their interpretation. Because imperatives beneficial to the hearer receive a positive interpretation, we assume they are not considered impolite.

Our second prediction was that adding alsjeblieft 'please' would make the interpretation of an imperative more negative, especially for imperatives beneficial to the hearer. This prediction was not borne out. Although the speaker of Maak er een leuke dag van 'Have a nice day' was often interpreted as kind or friendly, 
whereas adding alsjeblieft 'please' also triggered the choice of irritated and unfriendly, we did not find a significant difference between the imperatives with and without alsjeblieft 'please'. Adding alsjeblieft 'please' does not make imperatives more negative, but it does not make them more positive either. Since we assume that positivity and politeness are related in the interpretation of imperatives, we may conclude that alsjeblieft 'please' does not function as a politeness marker in Dutch imperatives.

Our third hypothesis that imperatives, especially the ones in the speaker's interest, receive a more positive interpretation when discourse particles are added, was confirmed by the data. Adding particles resulted in a more positive interpretation of the imperatives beneficial to the speaker. These utterances are probably perceived as more polite, therefore.

Much of the variation was not accounted for by our analysis. For instance, a speaker uttering Ruim de keuken op 'Clean up the kitchen' was considered bossy or angry, but when alsjeblieft 'please' was added, this often changed to irritated or impatient. Since these four properties are all scored as 'negative', we cannot account for the difference in interpretation in our analysis. By contrast, when the two discourse particles were added to this imperative, the speaker got more often interpreted as neutral or even kind. As this involves a change from 'negative' to 'non-negative', our analysis does take it into account.

\section{Conclusion}

The results of our experiment on the interpretation of Dutch imperatives confirm that a distinction can be made between imperatives beneficial to the speaker and imperatives beneficial to the hearer. The former receive a negative interpretation, but the latter a positive one. This can be taken as evidence that imperatives beneficial to the hearer are not considered impolite. Adding the politeness marker alsjeblieft 'please' to an imperative in Dutch does not make its interpretation more or less positive, which indicates that in imperative contexts alsjeblieft 'please' is mainly functioning as a speaker-oriented discourse marker, and less so as a politeness marker. Adding the mitigating discourse particles maar and even does make the interpretation of an imperative in the speaker's interest more positive, hence more polite. 


\section{Acknowledgments}

We would like to thank our colleagues from the research group Grammar and Cognition in Nijmegen, especially Ruti Vardi, as well as the audience at the TIN-dag 2016, and two anonymous reviewers for helpful comments and discussion.

\section{References}

Blum-Kulka, S. 1987. "Indirectness and politeness in requests: same or different?" Journal of Pragmatics 11.131-146. doi: 10.1016/0378-2166(87)90192-5

Brown, Penelope \& Stephen Levinson. 1978. "Universals in language use: politeness phenomena”. Questions and politeness. Strategies in social interaction ed. by E.N. Goody, 56-289. Cambridge: Cambridge University Press.

Clark, H. H. \& D. H. Schunk. 1980. "Polite responses to polite requests". Cognition 8.111-143. doi: 10.1016/0010-0277(80)90009-8

Curl, T. S. \& P. Drew. 2008. "Contingency and action: a comparison of two forms of requesting". Research on Language and Social Interaction 41.129-153. doi: 10.1080/08351810802028613

de Haan, Sies. 1992. "Vul de bon in en win een reis!' Over imperatieven in reclameteksten". De kunst van de grammatica. Artikelen aangeboden aan Frida Balk-Smit Duyzentkunst bij haar afscheid als hoogleraar Taalkunde van het hedendaags Nederlands aan de Universiteit van Amsterdam ed. by E.G. Schermer-Vermeer, W.G. Klooster \& A.F. Florijn, 95-109. Amsterdam: Universiteit van Amsterdam.

Ervin-Tripp, S. 1976. "Is Sybil there? The structure of some American English directives". Language in Society 5.25-66. doi: 10.1017/Soo47404500006849

Fortuin, E. \& R. Boogaart. 2009. "Imperative as conditional: From constructional to compositional semantics". Cognitive Linguistics 20.641-673. doi: 10.1515/COGL.2009.028

Grice, H. Paul. 1975. "Logic and conversation". Syntax and Semantics, 3: Speech Acts ed. by P. Cole \& J. L. Morgan, 41-58. New York: Academic Press.

Hamblin, Charles L. 1987. Imperatives. New York: Basil Blackwell.

Hobbes, Thomas. 1651. Leviathan. <https://www.gutenberg.org/files/3207/3207-h/3207-h. htm> (5 June 2016).

Hogeweg, L., E. McCready \& G. Winterstein. 2012. "Formal approaches to discourse particles and modal adverbs". Sprache und Datenverarbeitung: International Journal for Language Data Processing. 35/36.5-10.

Jary, Mark \& Mikhail Kissine. 2014. Imperatives. Cambridge: Cambridge University Press. doi: $10.1017 / C B O 9780511998126$

Kirsner, Robert S. 2003. "On the interaction of the Dutch pragmatic particles hoor and hè with the imperative and Infinitivus Pro Imperativo". LOT Occasional Series 1.59-96. Utrecht: LOT Publications.

Leech, Geoffrey N. 1983. Principles of pragmatics. London: Longman.

Leech, Geoffrey N. 2014. The pragmatics of politeness. Oxford: Oxford University Press. doi: 10.1093/acprof:oso/9780195341386.001.0001 
Mulder, Gijs. 1998. Indirecte en directe directieven in het Spaans: een analytisch en empirisch onderzoek naar taalhandelingen in het Spaans. (University of Amsterdam, PhD dissertation) Den Haag: Holland Academic Graphics.

Pfister, J. 2010. “Is there a need for a maxim of politeness?" Journal of Pragmatics 42.1266-1282. doi: 10.1016/j.pragma.2009.09.001

Proeme, H. 1984. “Over de Nederlandse imperativus”. Forum der Letteren 25.241-258.

Rossi, G. 2012. "Bilateral and unilateral requests: the use of imperatives and $M i X$ ? interrogatives in Italian". Discourse processes 49.426-458. doi: 10.1080/0163853X.2012.684136

Sato, S. 2008. "Use of 'please' in American and New Zealand English". Journal of Pragmatics 40.1249-1278. doi: 10.1016/j.pragma.2007.09.001

Searle, John R. 1975. “Indirect speech acts”. Syntax and Semantics, 3: Speech Acts ed. by P. Cole and J. L. Morgan, 59-82. New York: Academic Press.

Trosborg, Anna. 1995. Interlanguage pragmatics: Requests, complaints, and apologies. Berlin: De Gruyter. doi: 10.1515/9783110885286

Vismans, R. 1994. "Beleefdheid, Nederlandse modale partikels en het 'partikelloze' Engels". Colloquium Neerlandicum 12.269-291.

Watts, Richard J. 2003. Politeness. Cambridge: Cambridge University Press. doi: $10.1017 / C B O 9780511615184$

Wichmann, A. 2004. “The intonation of please-requests: a corpus-based study". Journal of Pragmatics 36.1521-1549. doi: 10.1016/j.pragma.2004.03.003

\section{Authors' addresses}

Helen de Hoop

Radboud University Nijmegen

Centre for Language Studies

P.O. Box 9103

6500 HD Nijmegen

The Netherlands

h.dehoop@let.ru.nl

Jetske Klatter

Radboud University Nijmegen

Centre for Language Studies

P.O. Box 9103

6500 HD Nijmegen

The Netherlands

j.klatter@let.ru.nl
Gijs Mulder

Radboud University Nijmegen

Centre for Language Studies

P.O. Box 9103

6500 HD Nijmegen

The Netherlands

g.mulder@let.ru.nl

Tijn Schmitz

Radboud University Nijmegen

Centre for Language Studies

P.O. Box 9103

6500 HD Nijmegen

The Netherlands

t.p.a.schmitz@student.ru.nl 